\title{
Perencanaan Modifikasi Jembatan Kali Legi Menggunakan Busur Baja dengan Lantai Kendaraan Di Tengah (A Half Through Arch)
}

\author{
Emilia Nur Apriani Sutisna dan Endah Wahyuni \\ Departemen Teknik Sipil, Fakultas Teknik Sipil, Lingkungan, dan Kebumian \\ Institut Teknologi Sepuluh Nopember (ITS) \\ E-mail: endah@ce.its.ac.id
}

\begin{abstract}
Abstrak-Jembatan Kali Legi yang berada di Kabupaten Blitar Jawa Timur merupakan akses utama transportasi menuju ke Malang, atau sebaliknya. Perencanaan awal jembatan ini merupakan jembatan dengan kontruksi gelagar beton prategang, dengan panjang total jembatan 325 meter. Dalam penulisan ini akan direncanaan Jembatan Kali Legi Blitar menggunakan sistem busur baja dengan lantai kendraan di tengah (A Half Through Arch Bridge) 2 bentang 100 meter, dan 125 meter jembatan pratekan dengan 4 pilar. Pada perencanaannya, di dapatkan tebal pelat lantai Kendaraan 20 cm. Profil gelagar memanjang yang digunakan yaitu WF $450 \mathrm{x}$ $200 \times 9 \times 14$ serta profil gelagar melintang WF $900 \times 300 \times 18 \times$ 34. Selanjutnya tahap perhitungan struktur utama dan sekunder dilakukan dengan menghitung beban-beban yang bekerja sehingga didapatkan profil box untuk rangka utama jembatan busur. Setelah dilakukan perhitungan dan kontrol jembatan busur, direncanakan dimensi dari bangunan bawah jembatan (pilar). Digunakan pilar dengan 1 kolom pier serta kebutuhan tiang pancang 36 buah dengan panjang 20 meter. Hasil perhitungan dituangkan dalam gambar teknik standar.
\end{abstract}

Kata Kunci-Jembatan busur, Box Baja, Pilar, Tiang Pancang.

\section{PENDAHULUAN}

$\mathrm{I}^{\mathrm{N}}$ NFRASTRUKTUR merupakan sarana untuk memperlancar roda perekonomian dan mempengaruhi semua aspek kehidupan dalam memenuhi kebutuhan. Untuk menunjang peningkatan kebutuhan tersebut dibutuhkan infrastruktur yang memadai, salah satunya adalah jembatan. Guna meningkatkan kelancaran arus lalu lintas kendaraan dan barang khususnya pada jalur Blitar-Malang serta mendukung pembangunan Jalur Lintas Selatan (JLS), Dinas Pekerjaaan Umum Propinsi Jawa Timur membuat Jembatan Kali Legi. Perencanaan jembatan ini diharapkan akan mampu mendorong pengembangan wilayah serta perekonomian untuk kedua wilayah tersebut.

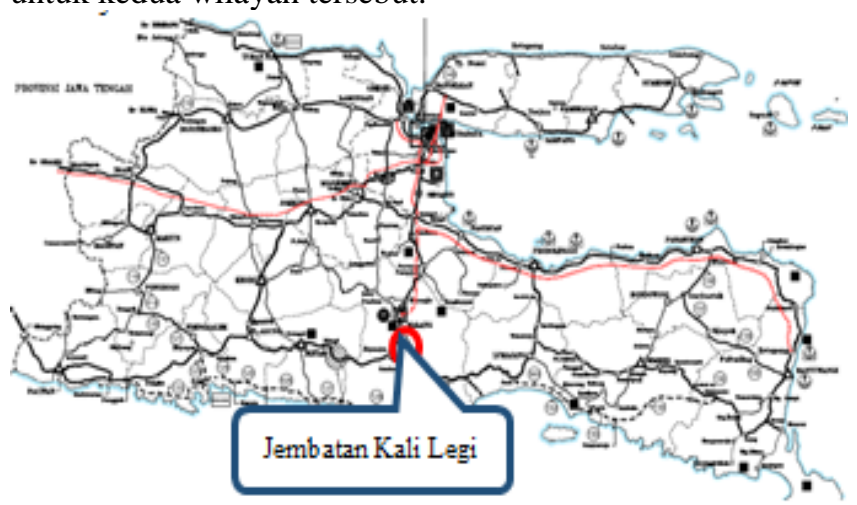

Gambar 1. Lokasi Jembatan Kali Legi
Jembatan Kali Legi yang berada di Kabupaten Blitar Jawa Timur merupakan akses utama transportasi menuju ke Malang, atau sebaliknya (lihat Gambar 1). Perencanaan awal jembatan ini merupakan jembatan dengan kontruksi gelagar beton prategang. Lebar lantai dengan panjang total jembatan 325 meter. Jembatan ini dibagi delapan bagian dengan sembilan pilar, lima bagian dengan bentang 50 meter dan tiga bagian bentang satu bagian 25,00 meter (lihat Gambar 2). Penggunaan gelagar beton prategang dengan pilar banyak menimbulkan keborosan design jembatan ini dan terkesan kaku. Karena beton prategang hanya memliki kapasitas bentang maksimal $40 \mathrm{~m}$. Sedangkan pada kenyataannya bentang dipasang 50,60 meter. Dengan panjang total 325 meter maka dibutuhkan pilar yang banyak untuk menopang gelagarnya.

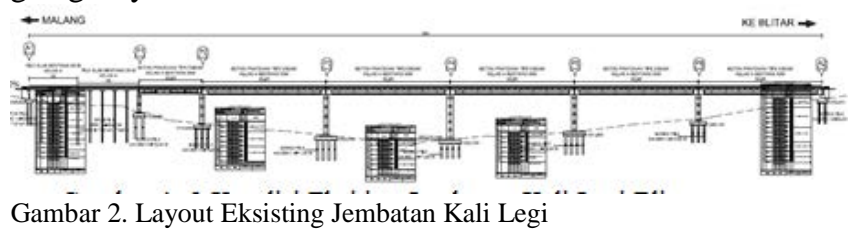

Dalam penulisan ini akan direncanakan Jembatan Kali Legi Blitar menggunakan sistem busur baja dengan lantai kendraan di tengah (A Half Through Arch Bridge). Perencanaan jembatan busur baja pada jembatan ini karena untuk bentang 60-500 meter akan lebih efektif[1]. Bentuk busur pada jembatan ini berguna untuk mengurangi momen lentur di lapangan, sehingga lebih efisien daripada gelagar paralel. Pemilihan penampang box material baja sebagai pemikul utama juga memiliki kekuatan yang cukup tinggi dengan luas penampang relatif lebih langsing daripada material beton. Sifat daktilitas baja yang mengalami deformasi besar di bawah pengaruh tegangan tarik tinggi mampu mencegah robohnya struktur tiba-tiba[2], [3]. Struktur busur juga dapat mengurangi kebutuhan pilar jembatan sehingga tidak terjadi perubahan penampang sungai, Pada perencanaan Jembatan Kali Legi Blitar menggunakan sistem busur baja dengan lantai kendraan di tengah (A Half Through Arch Bridge) 2 bentang 100 meter, dan 125 meter jembatan pratekan dengan 4 pilar. Dengan adanya desain Jembatan Kali Legi yang baru ini diharapkan mampu menjawab sebuah tantangan dalam merancang sebuah jembatan yang kuat dan efisien serta mampu meningkatkan nilai estetika dan memberi kesan monumental. 


\section{TINJAUAN PUSTAKA}

\section{A. Umum}

Dalam merencanakan sebuah jembatan terdapat beberapa pertimbangan dalam segi ekonomis maupun teknis yang disesuaikan dengan tingkat kebutuhan. Secara umum, jembatan busur adalah sebuah jembatan yang mempunyai bentuk struktur setengah parabola dengan abutmen di kedua sisi jembatan. Struktur setengah parabola tersebut merupakan rangka utama dari jembatan yang fungsinya menerima semua gaya-gaya yang bekerja pada jembatan.

\section{B. Jembatan Busur}

Konstruksi pelengkung pada jembatan merupakan rangka utama dari jembatan yang berfungsi menerima semua gayagaya yang bekerja pada jembatan. Pada prinsipnya konstruksi dari jembatan busur dapat memberikan reaksi horizontal akibat beban vertikal yang bekerja, selain itu jembatan busur dapat menerima momen lentur lebih efisien dibandingkan dengan gelagar paralel.

\section{Sambungan}

1) Sambungan Baut

Sebuah sambungan baut yang memikul gaya terfaktor, $\mathrm{Ru}$, harus direncanakan sedemikian rupa sehingga selalu terpenuhi[4], [5]:

$$
\mathrm{R}_{\mathrm{u}} \leq \varnothing \mathrm{R}_{\mathrm{n}}
$$

\section{Struktur Bangunan Bawah}

Struktur bangunan bawah jembatan adalah bagian dari struktur jembatan yang umumnya terletak di sebelah bawah bangunan atas dengan fungsi untuk menerima dan memikul beban dari bangunan atas agar dapat disalurkan kepada pondasi. Bangunan bawah dibagi menjadi 2 (dua) bagian yaitu kepala jembatan (abutment) atau pilar (pier) dan pondasi untuk kepala jembatan atau pilar. Struktur bangunan bawah perlu didesain khusus sesuai dengan jenis kekuatan tanah dasar dan elevasi jembatan.

1) Pilar Jembatan (Pier)

Pada umumnya, pilar diletakkan ditengah bentang jembatan sehingga terkena pengaruh aliran sungai. Untuk menanggulangi masalah tersebut maka pada perencanaannya, direncanakan selain segi kekuatannya juga di lihat pula dari segi keamanannya.

2) Pondasi

Pondasi adalah suatu bagian dari konstruksi bangunan yang bertugas meletakkan bangunan dan meneruskan beban bangunan atas dan bangunan bawah ke dasar tanah yang cukup kuat mendukungnya.

\section{METODOLOGI}

Tahapan- tahapan dari Modifikasi Struktur Jembatan Kali Legi ini, dimulai dengan preliminary design jembatan busur, lalu perencanaan struktur sekunder dan dilanjutkan tahap pemodelan dan analisa struktur untuk mendapatkan dimensi pada struktur utama jembatan busur. Pada tahap pemodelan struktur di analisa pada 2 kondisi yaitu kondisi normal dan kondisi putus kabel. Setelah didapatkan dimensi pada struktur atas dilanjutkan perhitungan struktur bawah. Semua hasil perencanaan modifikasi jembatan Kali Legi dituangkan dalam bentuk gambar struktur. Sehingga dapat dilihat tahapan-tahapan pengerjaan studi ini pada Gambar 3.

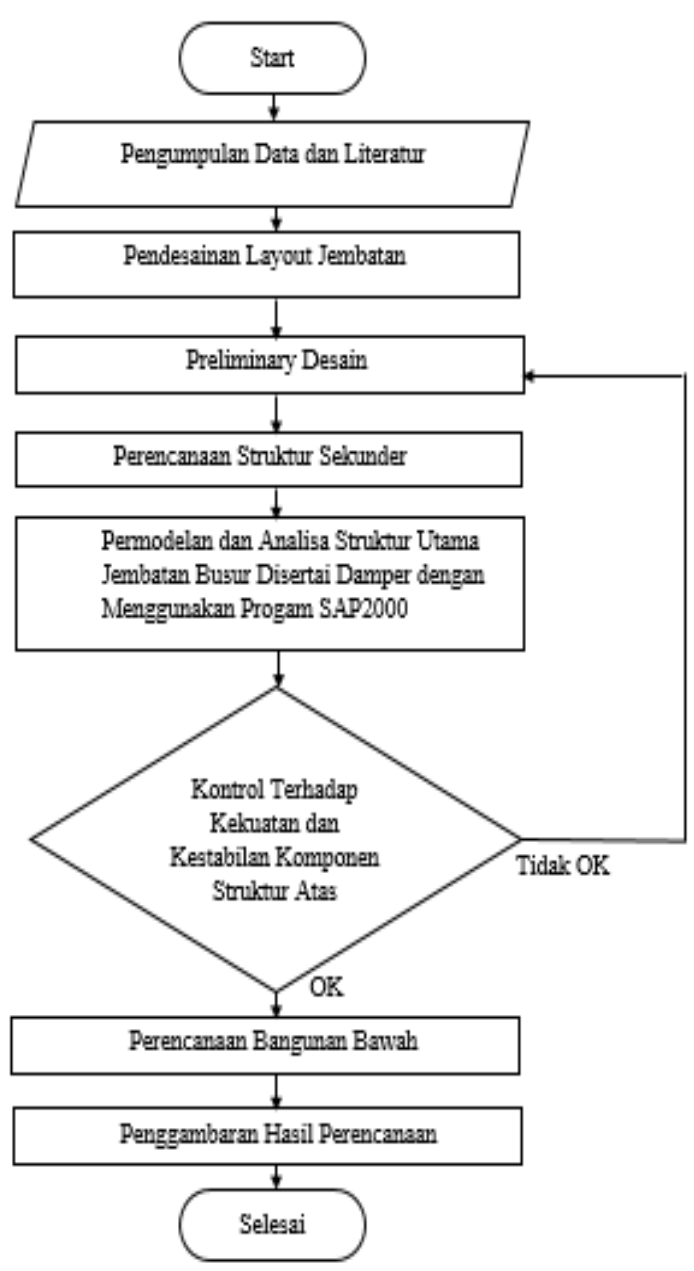

Gambar 3. Diagram Alir

\section{HASIL PENGOLAHAN DATA}

\section{A. Pembebanan}

Studi ini memodelkan Jembatan Busur sesuai dengan pembebanan yang diatur pada SNI 1725-2016, yaitu sebagai berikut[6]:

Beban Mati

Beton $=2277 \mathrm{~kg} / \mathrm{m}^{3}$

Aspal $=2200 \mathrm{~kg} / \mathrm{m}^{3}$

Beban Lajur D

$$
\begin{aligned}
\text { Q UDL } & =\mathrm{q} \times \gamma^{\mathrm{U}} \mathrm{TD} \\
& =18.0 \mathrm{kN} / \mathrm{m}^{2} \\
\mathrm{Q} \text { BGT } & =\mathrm{p} \times \gamma^{\mathrm{U}} \mathrm{TD} \\
& =98.0 \mathrm{kN} / \mathrm{m}
\end{aligned}
$$

Beban Truck

$$
\begin{aligned}
\text { Q TT } & =112,5 \mathrm{kN} \times(1+\text { FBD }) \times \gamma^{\mathrm{U}} \\
& =292,5 \mathrm{kN}
\end{aligned}
$$

Beban Temperatur

Temperatur $=25^{0}$ celcius

Beban Angin

1) Beban Angin Horizontal

$$
\begin{aligned}
& \mathrm{v}_{\mathrm{DZ}}=2,5 \mathrm{v}_{\mathrm{o}}\left(\frac{\mathrm{v}_{10}}{\mathrm{v}_{\mathrm{B}}}\right) \ln \left(\frac{\mathrm{z}}{\mathrm{z}_{\mathrm{o}}}\right) \\
& \mathrm{v}_{\mathrm{DZ}}=119,11 \mathrm{~km} / \mathrm{jam}
\end{aligned}
$$

2) Beban Angin pada Struktur Untuk rangka, kolom, dan pelengkung

$\mathrm{PD}$ tekan $=0,0042 \mathrm{Mpa}$ $\mathrm{PD}$ hisap $=0,0021 \mathrm{MPa}$

Beban Gempa 
Untuk perhitungan gaya gempa direncanakan menggunakan perhitungan analisa statik berdasarkan RSNI gempa 2833-2013 tentang tata cara pembebanan gempa untuk jembatan, sebagai berikut[7]:

$$
\mathrm{EQ}=\frac{\mathrm{Cm}}{\mathrm{R}} \mathrm{Wt}
$$

Dimana :

EQ : gaya gempa horizontal statis

Csm : koefesien respon gempa elastik

$\mathrm{Wt}$ : berat total struktur

$\mathrm{R}$ : faktor modifikasi respon

Untuk perencanaan gaya gempa yang dihasilkan pada analisa dinamis, dimana letak bangunan terletak pada zona 4. Berdasarkan data tanah yang telah dihitung tanah termasuk tanah lunak $(\mathrm{N}<15)$, maka:

- Percepatan puncak di batuan dasar (PGA) : 0,334g

- Percepatan 0,2 detik di batuan dasar (Ss) : 0,643g

- Percepatan 1 detik di batuan dasar (S1) : 0,34 g

Kemudian mencari periode dari SAP 2000 berdasarkan untuk perhitungan koefisien respon gempa elastik (Csm), didapatkan:

- $\mathrm{T}$ arah $\mathrm{x}=0,539 \rightarrow \mathrm{T} 0>\mathrm{T}>\mathrm{Ts}$

- $\mathrm{T}$ arah $\mathrm{y}=0,6629 \rightarrow \mathrm{T} 0>\mathrm{T}>\mathrm{Ts}$

Berdasarkan angka tersebut maka termasuk dalam ketentuan $\mathrm{Csm}=\mathrm{SDS}=0.7716$.

Eqx arah memanjang $(\mathrm{X})$

$$
E q=\frac{0.7716}{1.5} \times 3948.119 K N=2030,912 K N
$$

Eqy arah melintang $(\mathrm{Y})$

$$
E q=\frac{0.7716}{1.5} \times 3948.119 K N=2030,912 K N
$$

Kombinasi beban yg digunakan sesuai SNI 1726:2016 Tabel 1[6]:

- $\quad$ KUAT 1 :

1,3MS+2MA+1.8TD+1.8TB+1.8TP+1EUn

- $\quad$ KUAT 3 : 1.3MS+2MA+1.4EWs+1Eun

- EKSTREM 1 :

1.3MS+2MA+0.5TD+0.5TB+0.5TP+0.3EQx+1EQy

Pada permodelan struktur jembatan menggunakan SAP2000, digunakan permodelan 3 dimensi untuk mencari gaya aksial batang maksimum sesuai garis pengaruh batang akibat beban berjalan yang kemudian dijadikan acuan untuk mendesain profil batang yang digunakan sesuai gaya batang yang terjadi. Berikut ini adalah pemodelan struktur dari perencanaan untuk mendapatkan dimensi buhsur dan dikontrol sesuai dengan peraturan SNI T-03-2005[8], [9].

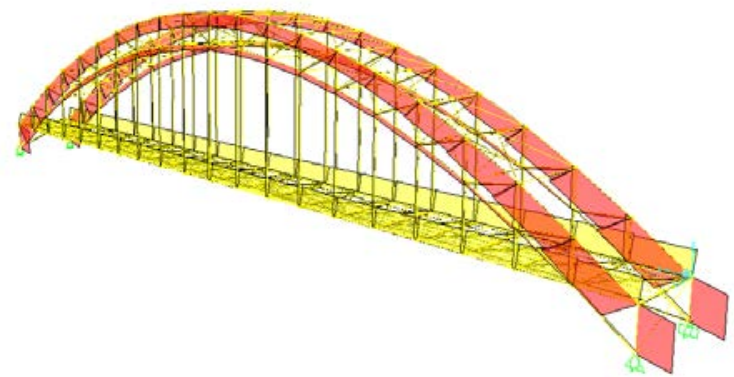

Gambar 4. Aksial Forces Akibat Kombinasi Kuat 1

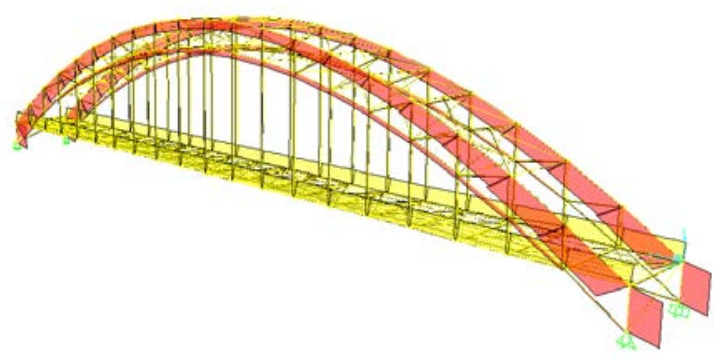

Gambar 5. Aksial Forces Akibat Kombinasi Kuat 3

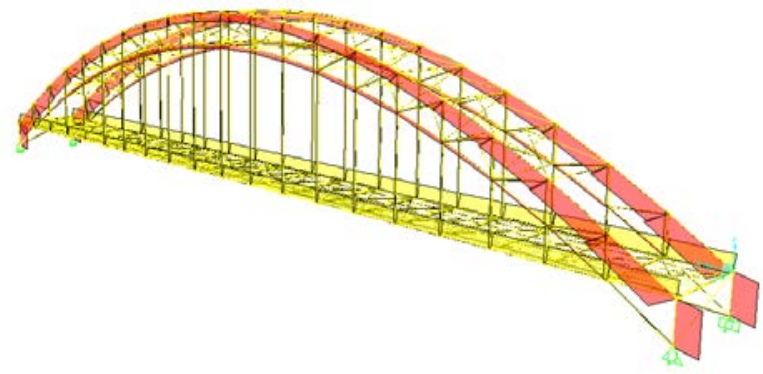

Gambar 6. Aksial Forces Akibat Kombinasi Ekstrem 1

\section{B. Pelat Lantai}

Sehingga direncanakan :

Tebal $=200 \mathrm{~mm}$

Tebal aspal $=50 \mathrm{~mm}$ (SNI 1725:2016 Psl. 7.3.1) [9]

Penulangan Lentur Pelat

$\mathrm{P}_{\text {min }}<\rho_{\text {perlu }}<\rho_{\text {maks }}$

$0,0039<0,0064<0,0314(\mathrm{OK})$

$\mathrm{As}_{\text {perlu }}=\rho_{\text {perlu }} \times \mathrm{b} \mathrm{x} \mathrm{d}_{\mathrm{x}}=978,319 \mathrm{~mm}^{2}$

Dipakai tulangan D16-200 mm

$\mathrm{As}_{\text {pakai }}=1005,31 \mathrm{~mm}^{2}$

Syarat:

$\mathrm{As}_{\text {pakai }}>\mathrm{As}_{\text {perlu }}$

1005,31 $\mathrm{mm}^{2}>978,319 \mathrm{~mm}^{2}$ (OK)

Penulangan Susut Pelat

$\mathrm{AS}_{\text {perlu }}=0,002 \mathrm{x}$ b x dy

$$
=278 \mathrm{~mm}^{2}
$$

Jadi dipasang tulangan Ø13-450mm

As $_{\text {pakai }}=295,08 \mathrm{~mm}^{2}$

Syarat:

As pakai> As susut

295,08 $\mathrm{mm}^{2}>278 \mathrm{~mm}^{2}(\mathrm{OK})$

Kontrol Geser Pons

$\mathrm{V}_{\mathrm{U}}<\varphi \mathrm{Vc}$

292,5 kN < 386,519 kN (OK)

\section{Balok Memanjang}

Profil Yang Digunakan WF 450.200.9.14

Kontrol Kapasitas Momen

$\varnothing \mathrm{Mn} \geq \mathrm{Mu}$

423,081 kNm > 399,7 kNm (OK)

Kontrol Kapasitas Geser

$\varnothing \mathrm{Vn} \geq \mathrm{Va}$

634,23 kN > 292,5 kN (OK)

Interaksi Geser dan Lentur

$\frac{\mathrm{Mu}}{\varphi \mathrm{Mn}}+0,625 \frac{\mathrm{Vu}}{\varphi \mathrm{Vn}} \leq 1,375$

$1,233<1,375$ (OK)

Kontrol Lendutan

$\delta_{(\mathrm{T})} \leq \delta_{\mathrm{ijin}}$

$0,568 \leq 0,63(\mathrm{OK})$ 


\section{Balok Melintang}

Profil Yang Digunakan WF 900.300.18.34

Kontrol Kapasitas Momen

$\varnothing \mathrm{Mn} \geq \mathrm{Mu}$

2844,9 kNm > 400,85 kNm (OK)

Kontrol Kapasitas Geser

$\varnothing \mathrm{Vn} \geq \mathrm{Va}$

2536,92 kN > 828,8 kN (OK)

Interaksi Geser dan Lentur

$$
\frac{\mathrm{Mu}}{\varphi \mathrm{Mn}}+0,625 \frac{\mathrm{Vu}}{\varphi \mathrm{Vn}} \leq 1,375
$$

$0,33<1,375(\mathrm{OK})$

Kontrol Lendutan

$$
\delta_{(\mathrm{T})} \leq \delta_{\text {ijin }}
$$

$0,797 \leq 1,125(\mathrm{OK})$

Sambungan Balok Melintang dan Balok Memanjang

Baut Tipe A325 tipe friksi

Diameter baut $(\mathrm{db}) \quad=20 \mathrm{~mm}$

Diameter lubang $(\mathrm{d} 1)=22 \mathrm{~mm}$

Pelat Siku 120 x 120 x 15

Jumlah baut pada balok memanjang $\mathrm{n}=\frac{\mathrm{Vu}}{\varphi \mathrm{Rn}}=\frac{32215,31}{11470}=3$

Jumlah baut pada balok melintang $n=\frac{\mathrm{Vu}}{\varphi \mathrm{Rn}}=\frac{32215,31}{11470}=3$

Jarak antar baut $=60 \mathrm{~mm}$

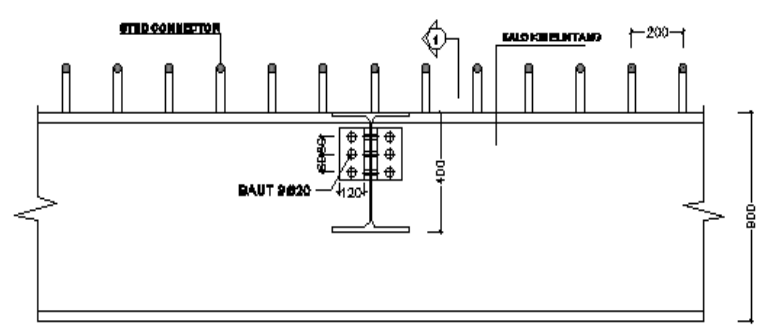

Gambar 7. Sambungan Balok Melintang dan Balok Memanjang

\section{E. Ikatan Angin Atas}

Profil Yang Digunakan Box 180 x 180 x 6,3 x 6,3

Kontrol Tekan

$$
\emptyset P n=62128,48 \mathrm{Kg}>P u=25060,9 \mathrm{Kg}(\mathrm{OK})
$$

Kontrol Tarik

Kuat Putus $\emptyset P n=15275,55 \mathrm{Kg}>1188,3 \mathrm{Kg}$

(OK)

Kuat Leleh $\emptyset P n=13549,995 \mathrm{Kg}>1188,3 \mathrm{Kg}$

(OK)

Sambungan Ikatan Angin Atas tipe tumpu dan geser

Diameter baut $(\mathrm{db})=24 \mathrm{~mm}$

Diameter lubang $(\mathrm{d} 1)=22 \mathrm{~mm}$

Kebutuhan baut $\mathrm{n}=\frac{\mathrm{Ru}}{\varphi \mathrm{Rn}}=\frac{32844,5}{8305,5}=4$ buah baut

Jarak antar baut $=80 \mathrm{~mm}$

\section{F. Bracing Portal Akhir}

Profil Yang Digunakan Box 180 x 180 x 6,3 x 6,3

Kontrol Tekan

$$
\varnothing P n=147007.71 \mathrm{Kg}>P u=29818.19 \mathrm{Kg} \quad(\mathrm{OK})
$$

Kontrol Tarik

Kuat Putus $\varnothing P n=39800.72 \mathrm{Kg}>20590.46 \mathrm{Kg} \quad(\mathrm{OK})$

Kuat Leleh $\varnothing P n=35304.75 \mathrm{Kg}>20590.46 \mathrm{Kg} \quad$ (OK)

Sambungan Bracing Portal Akhir tipe friksi

$$
\begin{array}{ll}
\text { Diameter baut (db) } & =20 \mathrm{~mm} \\
\text { Kebutuhan baut } & =6 \mathrm{buah} \\
\text { Jarak antar baut } & =100 \mathrm{~mm}
\end{array}
$$

\section{G. Kolom Portal Akhir}

Profil Yang Digunakan Box 500 x 500 x 20 x 20

Kontrol Tekan

$\emptyset P n=1250809.796 \mathrm{Kg}>P u=1236427.76 \mathrm{Kg}$

(OK)

Interaksi Aksial dan Lentur

$\frac{\mathrm{Nu}}{\varphi \mathrm{Nn}}+\frac{8}{9}\left(\frac{\mathrm{Mux}}{\varphi \mathrm{Mnx}}+\frac{\text { Muy }}{\varphi \mathrm{Mny}}\right) \leq 1$

$0,84<1(\mathrm{OK})$

\section{H. Ikatan Silang angin atas}

Profil Yang Digunakan Box 180 x 180 x 6,3 x 6,3

Kontrol Tarik

Kuat Putus $\emptyset P n=15275,55 \mathrm{Kg}>8050 \mathrm{Kg}$

(OK)

Kuat Leleh $\emptyset P n=13549,995 \mathrm{Kg}>8050 \mathrm{Kg} \quad(\mathrm{OK})$

Sambungan Bracing Portal Akhir tipe tumpu dan geser

Diameter baut $(\mathrm{db})=16 \mathrm{~mm}$

Kebutuhan baut $=3$ buah

Jarak antar baut $\quad=100 \mathrm{~mm}$

I. Ikatan Vertikal angin atas

Profil Yang Digunakan Box 180 x 180 x 6,3 x 6,3

Kontrol Tekan

$\emptyset \mathrm{Pn}=34732,22 \mathrm{Kg}>\mathrm{Pu}=6412.7 \mathrm{Kg} \quad(\mathrm{OK})$

Kontrol Tarik

Kuat Putus $\emptyset \mathrm{Pn}=15275,55 \mathrm{Kg}>6412.7 \mathrm{Kg} \quad$ (OK)

Kuat Leleh $\varnothing \mathrm{Pn}=13549,995 \mathrm{Kg}>6412.7 \mathrm{Kg} \quad$ (OK)

Sambungan Bracing Portal Akhir tipe tumpu dan geser

Diameter baut $(\mathrm{db})=16 \mathrm{~mm}$

Kebutuhan baut $\quad=4$ buah

Jarak antar baut $\quad=100 \mathrm{~mm}$

\section{J. Batang Pelengkung Busur}

- $\quad$ Profil Yang Digunakan Box 500 x 500 x 25 x 25 pada tepi busur atas segmen 1

Kontrol Tekan

$\emptyset \mathrm{Pn}=1298272,26 \mathrm{Kg}>\mathrm{Pu}=1189298.4 \mathrm{Kg} \quad$ (OK)

Sambungan Busur Batang Atas

Alat penyambung yang dipakai adalah :

Baut $\rightarrow \mathrm{db}=30 \mathrm{~mm}$; A 325

Maka jumlah baut yang dipakai $=90$

Jarak antar baut $=100 \mathrm{~mm}$

- Profil Yang Digunakan Box 400 x 400 x 16 x 16 pada tepi busur bawah

Kontrol Tekan

$\emptyset \mathrm{Pn}=625537,26 \mathrm{~kg}>\mathrm{Pu}=386780.8 \mathrm{Kg} \quad(\mathrm{OK})$

Kontrol Tarik

Kuat Putus $\emptyset \mathrm{Pn}=1127627 \mathrm{Kg}>224360.1 \mathrm{Kg} \quad$ (OK)

Kuat Leleh $\emptyset \mathrm{Pn}=729054 \mathrm{Kg}>224360.1 \mathrm{Kg} \quad$ (OK)

Sambungan Busur Batang Atas

Alat penyambung yang dipakai adalah :

Baut $\rightarrow \mathrm{db}=30 \mathrm{~mm} ; \mathrm{A} 325$

Maka jumlah baut yang dipakai $=36$

Jarak antar baut $=100 \mathrm{~mm}$

- $\quad$ Profil Yang Digunakan Box 180 x 180 x 8 x 8 pada busur vertikal

Kontrol Tarik 
Kuat Putus $\varnothing \mathrm{Pn}=190323,075 \mathrm{Kg}>165276.9 \mathrm{Kg}$ (OK)

Kuat Leleh $\emptyset \mathrm{Pn}=168823,8 \mathrm{Kg}>165276.9 \mathrm{Kg} \quad$ (OK)

Sambungan Busur Batang Atas

Alat penyambung yang dipakai adalah :

Baut $\rightarrow \mathrm{db}=30 \mathrm{~mm} ;$ A 325

Maka jumlah baut yang dipakai $=14$

Jarak antar baut $=100 \mathrm{~mm}$

\section{K. Batang Tarik Busur}

Profil Yang Digunakan Box 500 x 500 x 19 x 19

Kontrol Tarik

Kuat Putus $\emptyset \mathrm{Pn}=1252732.13 \mathrm{Kg}>532784.4 \mathrm{Kg}(\mathrm{OK})$

Kuat Leleh $\emptyset \mathrm{Pn}=1079919 \mathrm{Kg}>532784.4 \mathrm{Kg}$

Sambungan Batang Tarik dan Balok Melintang

(OK)

Baut Tipe A325

Diameter baut $(\mathrm{db}) \quad=20 \mathrm{~mm}$
Jumlah baut pada balok memanjang $\mathrm{n}=\frac{\mathrm{Vu}}{\varphi \mathrm{Rn}}=\frac{532784,4}{13249,25}=28$

Jarak antar baut $=90 \mathrm{~mm}$

L. Batang Penggantung

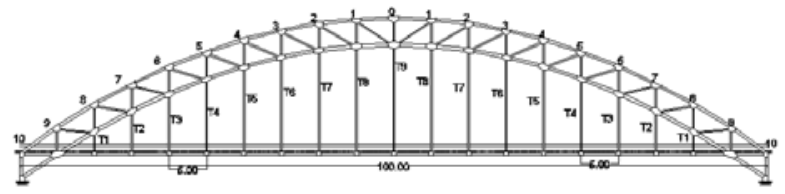

Gambar 8. Konstruksi Pemikul Utama

Diketahui:

Syarat:

Pu SAP $=104395.02 \mathrm{Kg}$

DWIDAG diameter $47 \mathrm{~mm}$ dengan $\mathrm{P}$ ijin $=104395.02 \mathrm{Kg}$

$\mathrm{Pu}<\varnothing \mathrm{Pn}$

$104395.02 \mathrm{Kg}<1310395,185 \mathrm{~kg}(\mathrm{OK})$

Sambungan Batang Penggantung

baut dengan diameter $30 \mathrm{~mm}$

Kekuatan geser

$$
\begin{aligned}
& \varnothing \mathrm{Rn}=1,13 \times \mu \times \mathrm{m} \times \mathrm{Tb} \\
& =1,13 \times 0,35 \times 1 \times 33500 \\
& =13249 \mathrm{~kg} \\
& \mathrm{n}=\frac{\mathrm{Ru}}{\emptyset \mathrm{Rn}}=\frac{104395.02 \mathrm{~kg}}{13249 \mathrm{~kg}}=7,879 \rightarrow 8 \text { baut } \\
& \text { jarak antar baut } 100 \mathrm{~mm}
\end{aligned}
$$

M. Perletakan

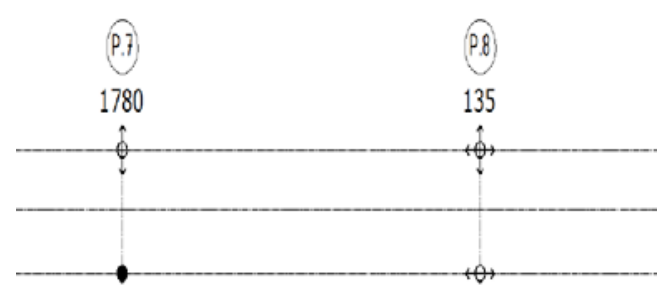

Gambar 9. Denah Perletakan Posisi Pot Bearing

Jenis perletakkan pada studi ini adalah Pot Bearing dengan brosur dari Freyssinet.

Dimana :

$\hat{\$}$ : pot bearing tipe unidirectional

: pot bearing tipe fixed (memungkinkan tidak adanya gerakan)

+ : pot bearing tipe multidirectional (memungkinkan 2 gerakan arah lateral )

- Unidirectional pot bearing, direncanakan unidirectional pot bearing tipe GG24000-1200-50
- Multinidirectional pot bearing, direncanakan multidirectional pot bearing tipe GL8000-50-20

- Fixed pot bearing, direncanakan fixed pot bearing tipe FX28000-1400

N. Pilar

Data Perencanaan

$\begin{array}{ll}\text { Dimensi pilar } & =3000 \times 3000 \mathrm{~mm} \\ \text { Panjang pilar } & =18,5 \mathrm{~m}\end{array}$

Mutu beton (f'c) $\quad=40 \mathrm{MPa}$

Diameter Tul. Utama (Ø) $=32 \mathrm{~mm}$

Mutu Baja (fy) $\quad=400 \mathrm{MPa}$

Elastisitas (Es) $\quad=200000 \mathrm{MPa}$

Selimut beton $\quad=50 \mathrm{~mm}$

Syarat:

$\mathrm{Pu}<\mathrm{P}$ ijin

$35236293 \mathrm{~N}<0,10$ f'c Ag

$35236293 \mathrm{~N}<0,10$ x 40 MPa x $3000 \mathrm{~mm}$ x $3000 \mathrm{~mm}$ $35236293 \quad \mathrm{~N}<36000000 \mathrm{~N}$ (Tekan diabaikan)Direncanakan menggunakan tulangan 120D32 (As $=108108 \mathrm{~mm}^{2}$ ) sesuai diagram interaksi pada Gambar 10 .

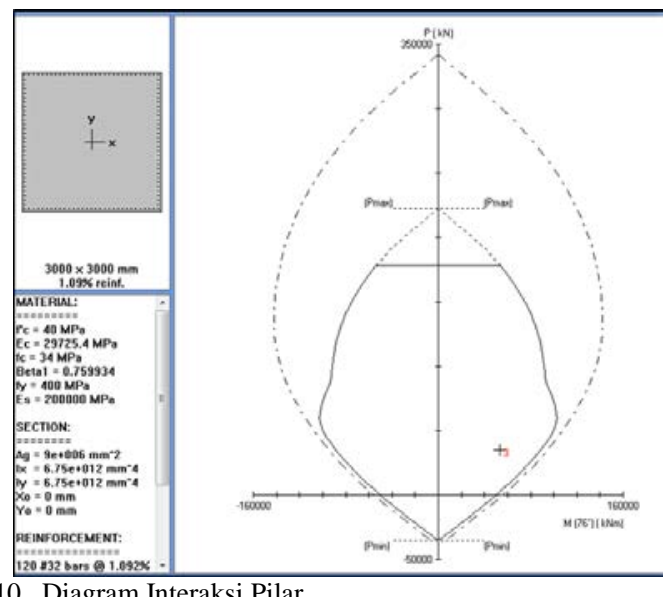

Gambar 10. Diagram Interaksi Pilar

Penulangan Geser Pilar

Syarat:

$\varnothing \mathrm{Vc} \geq \mathrm{Vu}$

$0,75 \times 12,031.81 \mathrm{kN} \geq 5207,655 \mathrm{kN}$

$9,023.86 \mathrm{kN}>5207,655 \mathrm{kN}(\mathrm{OK})$

Jadi dipasang sengkang D19-150 mm

O. Tiang Pancang

Data Perencanaan

Kedalaman tiang pancang $=20 \mathrm{~m}$

Diameter tiang pancang $(\mathrm{d})=80 \mathrm{~cm}$

Keliling tiang pancang (As) $=\pi \mathrm{d}=251,33 \mathrm{~cm}$

Luas tiang pancang (Ap) $=1 / 4 \pi \mathrm{d}^{2}$

$$
=1 / 4 \pi(80 \mathrm{~cm})^{2}
$$$$
=5026,55 \mathrm{~cm}^{2}
$$

Digunakan tiang pancang produksi WIKA Type C.

Sehingga $\mathrm{P}$ ijin bahan $=367,6$ Ton .

Jumlah Tiang

$$
\frac{\mathrm{n}}{\frac{=\Sigma \mathrm{P}}{\overline{\mathrm{P}} \mathrm{E}_{\mathrm{k}}}}=\frac{3523,629 \text { Ton }}{439,25 \text { Ton }}=9 \approx 36 \text { buah }
$$

P. Poer

Data Perencanaan

-Dimensi Poer (B x L) $\quad=9200$ x $11600 \mathrm{~mm}$

-Tebal Poer

$$
=1500 \mathrm{~mm}
$$

-Mutu Beton (f'c) = $\quad 35 \mathrm{MPa}$

-Diameter Tul. Utama (Ø) $=32 \mathrm{~mm}$

Mutu Baja (fy)

$=400 \mathrm{MPa}$ 


$$
\begin{array}{ll}
\text { Elastisitas (Ef) } & =200000 \mathrm{MPa} \\
\text {-Tebal Selimut Beton } & =40 \mathrm{~mm}
\end{array}
$$

Penulangan $\mathrm{X}$

Asperlu = 0,0113 x $1000 \times 1460=16454 \mathrm{~mm} 2$

$\mathrm{S}_{\text {perlu }}=98 \mathrm{~mm}$

Dicoba pasang tulangan 2D32 - $90 \mathrm{~mm}$

As perlu $\leq$ As pasang

$16454 \mathrm{~mm}^{2} \leq \frac{1 / 4 \pi \mathrm{d}^{2} \mathrm{~b}}{\mathrm{~s} \text { pasang }}$

$16454 \mathrm{~mm} 2 \leq 17872 \mathrm{~mm} 2$

Penulangan Y

Asperlu $=0,0068 \times 1000 \times 1460=9964 \mathrm{~mm} 2$

$\mathrm{S}_{\text {perlu }}=161 \mathrm{~mm}$

Dicoba pasang tulangan 2D32 - $150 \mathrm{~mm}$

As perlu $\leq$ As pasang

$9964 \mathrm{~mm}^{2} \leq \frac{1 / 4 \pi \mathrm{d}^{2} \mathrm{~b}}{\text { s pasang }}$

$9964 \mathrm{~mm} 2 \leq 10723 \mathrm{~mm} 2$

\section{KESIMPULAN}

1. Profil struktur sekunder dan primer menggunakan mutu baja BJ 55 dengan fy = $355 \mathrm{MPa}$ dan fu = $565 \mathrm{MPa}$ [14]. Dari hasil perhitungan struktur primer jembatan busur didapatkan:

- Batang penggantung DWIDAG $47 \mathrm{~mm}$

- Batang atas busur segmen 1 box 500 × 500 × 25 × 25

- Batang atas busur segmen 2 box 500 x 500 x 19 x 19

- Batang atas busur segmen 3 box 500 x 500 x 16 x 16

- Batang bawah busur box 400 x 400 x 16 x 16

- Batang vertikal busur box 180 x 180 × 8 × 8

- Batang diagonal busur box 180 x 180 x 10 x 10

- Batang tarik box 500 x 500 x 25 x 19

- Bracing portal akhir box 180 x 180 x 6,3

- Kolom Portal akhir box 500 x 500 x 25 x 25

- Ikatan silang angina rangka box 180 x 180 x 6,3 x 6,3

2. Perletakan menggunakan pot bearing dengan tipe:
- Undirectional tipe GG24000-1200-50

- Multidirectional tipe GL8000-50-20

- Fixed tipe FX28000-1400

3. Pilar jembatan berukuran tinggi 18,5 meter dengan kolom pilar panjang 3 meter dan lebar 3 meter di sertai pier head panjang 11 meter, lebar 4 meter, tinggi 1,5 . Dimensi poer berukuran panjang 21,2 meter lebar 9,2 meter dan tebal 3,5 meter. Mutu beton yang dipakai yaitu $\mathrm{f}^{\prime} \mathrm{C}=25 \mathrm{MPa}$ dan $40 \mathrm{MPa}$.

4. Pondasi struktur menggunakan tiang pancang PT. WIKA BETON dengan $\mathrm{D}=80 \mathrm{~cm}$ (type $\mathrm{C}$ ) dengan kedalaman 20 m berdasarkan hasil Daya Dukung Tanah dan material yang digunakan. Jumlah kebutuhan tiang pancang yaitu 36 buah pada masing-masing pilar.

\section{DAFTAR PUSTAKA}

[1] H. G. Septiawan, "Desain jembatan baru pengganti jembatan kutai kartanegara dengan sistem busur," Institut Teknologi Sepuluh Nopember, 2012.

[2] R. Prasmoro, H. S. Masiran, and E. Wahyuni, "Modifikasi jembatan sembayat baru II menggunakan sistem jembatan busur rangka," $J$. Tek. ITS, vol. 6, no. 1, pp. C13-C18, Mar. 2017.

[3] B. Mahardhika and E. Wahyuni, "Perencanaan modifikasi rangka busur baja pada jembatan pemali dengan damper sebagai longitudina stopper,” J. Tek. ITS, vol. 6, no. 1, pp. D7-D11, Mar. 2017.

[4] Badan Standardisasi Nasional, "Bridge management system (BMS) peraturan perencanaan teknik jembatan,” Jakarta, 1992.

[5] Badan Standarisasi Nasional (BSN), SNI 03-172-2002, Tata cara perencanaan struktur baja untuk bangunan gedung. Badan Standarisasi Nasional (BSN): Departemen Pekerjaan Umum, 2002

[6] Badan Standardisasi Nasional, SNI 1725:2006, Pembebanan untuk jembatan. Jakarta: Badan Standardisasi Nasional, 2016.

[7] Badan Standardisasi Nasional, SNI 2833:2016, Perencanaan jembatan terhadap beban gempa. Jakarta: Badan Standardisasi Nasional, 2016.

[8] Badan Standardisasi Nasional (BSN), RSNI T-03-2005, Standar perencanaan struktur baja untuk jembatan. Jakarta: Badan Standardisasi Nasional (BSN), 2005.

[9] A. Setiawan, Perencanaan struktur baja dengan metode LRFD, Edisi Kedua. Semarang: Erlangga, 2008. 